\title{
Monetary and Fiscal Influences on Economic Activity: The Foreign Experience
}

\author{
by MICHAEL W. KERAN
}

\begin{abstract}
The November 1968 and November 1969 issues of this Revmw included articles which developed and explained in some detail a procedture for testing the relative importance of monetary and fiscal influences on economic activity in the United States. The conclusions reached in those articles were that (except for the years covering World War II) monetary influences had a stronger, more predictable, and faster impact on economic activity than fiscal influences.
\end{abstract}

This article presents additional empirical evidence on the monetary - fiscal issue on the basis of data from eight foreign countries. The analysis of this foreign experience tends to confirm the results obtained for the United States. Because the test procedure is identical with that used and described in some detail in the previous articles, this article is devoted mainly to presenting and describing the empirical evidence.

NE OF THE major current debates among economists and policymakers in the United States and abroad deals with the relative importance of monetary and fiscal influences on economic activity. This debate reflects a growing awareness of the importance of monetary policy in any stabilization program. In part, this awareness stems from the intellectual resurgence of the quantity theory of money as an explanation of short-run movements in economic activity. In the main, however, it is probably due to the surprising number of recent historical experiences in which monetary actions have seemed to be effective and fiscal actions have seemed to be ineffective.

The two episodes best known to the American public are the tight money easy fiscal policy combination of 1966 which preceded the mini-recession in early 1967, and the easy money-tight fiscal policy combination of the last half of 1968 which was followed by continued economic boom in 1969. Similar experiences have occurred in other countries. In early 1968, for example, the United Kingdom had an easy money-tight fiscal policy combination and experienced a continued economic boom in the second half of 1968 and through early 1969.

This Review has recently published two articles analyzing the relative impact of monetary and fiscal influences on economic activity in the United States. ${ }^{1}$

\footnotetext{
1Leonall C. Andersen and Jerry L. Jordan, "Monetary and Fiscal Actions: A Test of Their Relative Importance in Economic Stabilization" in the November 1968 issue of this Revietw pp, 11-24; and Michael W. Keran, "Monetary and Fiscal Influences on Economic Activity - The Historical Evidence, in the November 1969 issue of this Review, pp. 5-24.
}

The conclusions reached in both articles were that monetary infuences have had a larger, more predictable, and faster effect on economic activity than fiscal influences. If the relationship observed in the United States reflects an important and stable underlying phenomenon, then one would expect that similar relationships would exist in other countries with roughly similar economic institutions. The intent of this article is to investigate comparable monetary and fiscal influences on economic activity for a selected group of foreign countries.

According to many authorities, the most desirable quality of any empirically-estimated equation is its accuracy in forecasting the future. According to Christ," "the 'future' should be interpreted to include anything unknown to the forecaster when he did his work." Thus, a significant test of the equation developed with respect to the United States would be to subject it to tests using data from other countries. With this in mind, this article should be viewed as an attempt not only to increase our understanding of monetary and fiscal relations in particular foreign countries, but also to provide an independent test of the "forecasting ability" of equations developed for the United States.

\footnotetext{
2Carl F. Christ, Econometric Models and Methods, (John Wiley and Sons, Inc., 1966). "Thus, a person might forecast some aspect of nineteenth century behavior by meats of theory and dati derived solely from the twentieth century," page 5. "Is there any truth in the maxim that prediction provides the acid test? The answer is yes. (If) ... we confront the model with an entirely new set of data which we were not familiar with when the model was chosen," page 547.
} 
This article will deal with these issues in the follow. ing order: first, a brief consideration of the test procedures; second, consideration of the data problems in making empirical tests of foreign countries; third, presentation of the statistical results; fourth, testing various propositions; and finally, some general obser. vations on the role of monetary infuences on economie activity.

\section{The Teng procedure}

The basic form of the equation used to test the relative impact of monetary and fiscal influences on economic activity is the same as that used in the previous articles in this Review. The general form of the test equation is:

$$
\Delta \mathrm{Y}=\mathrm{a}_{0}+\mathrm{a}_{1} \Delta \mathrm{M}+\mathrm{a}_{2} \Delta \mathrm{F},
$$

where: $\Delta \mathrm{Y}$ is a measure of changes in economic activity; $\Delta \mathrm{M}$ is a measure of changes in monetary influences; $\Delta \mathrm{F}$ is a measure of changes in fiscal influences; at and a: are symbols which represent the magnitude of the impact of monetary and fiscal influences, respectively, on economic activity; and $a_{0}$ represents the average impact of all other influences on economic activity during the same period.

The earlier articles presented a detailed discussion of the relative advantages and disadvantages of this "single equation" approach as opposed to alternative approaches to measuring monetary and fiscal influences. ${ }^{3}$ That discussion will not be repeated here.

The procedure employed in this article is to test two variables which are usually considered to be under the control of the monetary and fiscal policymakers to see which variable has the dominant impact on economic activity. These variables are not necessarily those which are consciously controlled by policy makers. Rather, the variables tested are those which

\footnotetext{
3One point should be emphasized. The "single equation" approach used here does not provide any direct evidence about whether the Keynesian Income-Expenditure theory or the Modern Quantity theory is the most appropriate explanation of national income. The reason for this is because the "single equation" test used in this article does not discriminate between the behavioral assumptions of the two theories. See Keran, pp. 6-8 for further discussion of this and re lated issues. It is theoretically possible to have a strong and prompt monetary infuence on economic activity in a Keynesian model. Such a model was estimated empirically by 3 . Ernest Tanner in "Lags in the Effects of Monetary Policy," American Economic Review, December 1969.

A single equation test of behavioral assumptions of The Quantity Theory and Income-Expenditure Theory, was made by Milton Friedman and David Meiselman in "Relative Stability of Income Velocity and Investment Multiplier in the United States, 1868-1960," Stabilization Policies, Prentice Hall, 1963. The September 1965 issue of the American Economic Review is devoted to a searching fiscussion of the Frtedman-Meiselman results.
}

both the Modem Quantity theory and the Keynesian Income-Expenditure theory would imply are the best measures of the impact of monetary and fiscal actions. Because this approach omits direct consideration of the channels through which the monetary or fiscal effects operate, it cannot be used to answer questions about the underlying structure of the economy.

\section{Fonelgn Data Problems}

When American researchers attempt to collect data on some facet of the American economy, they are doubly blessed. First, the United States publishes more statistics in greater detail and generally of greater accuracy than other countries. Second, expert knowledge of the sources and reliability of the data are readily available.

In general, neither the quantity nor quality of foreign data are as good as that for the United States. Furthermore, the American research worker is unlikely to be as familiar with the sources of foreign data as with domestic data.

Apparently, only four countries besides the United States have quarterly GNP data: Canada, Germany, Japan, and the United Kingdom. For reasons discussed in the Appendix, GNP results for the United Kingdom are not used in the main body of this article. For the United Kingdom and the other coun tries in our survey group, for which quarterly GNP data were not available, namely, Belgium, France, Italy, and the Netherlands, economic activity was measured on the basis of a proxy variable. The proxy variable for economic activity is equal to the scaled product of the seasonally adjusted industrial production index and the consumer price index ${ }^{4}$ times GNP in the base years of those indexes. As is shown in the Appendix, the proxy variable gives substantially the same implications for monetary and fiscal actions as the GNP measure in those countries in which both measures are available.

Using GNP data where available, and the proxy where GNP data was not available, provides quarterly measures of economic activity for eight of the major foreign industrial countries which have reasonably decentralized economic systems, and therefore come closest to paralleling the American economic system. For purposes of comparison, updated results from earlier studies on the United States are also presented.

tThe consumer price index is not seasonally adjusted. The exact formula is presented in the Appendix. 
The measure of monetary influence used for each country was the money stock as defined by the International Monetary Fund (IMF) in its International Financial Statistics. This was the only monetary variable which was available quarterly on a consistent basis for all countries. ${ }^{5}$ However, it would be desirable in fature research to try other monetary variables, such as the monetary base or total reserves of the banking system.

The most serious data problems were encountered in developing an appropriate fiscal variable. Possible measures of the fiscal influence are total Government spending (including transfer payments as well as purchases of goods and services), high-employment tax receipts, the differences between government spend. ing and high-employment tax receipts, ${ }^{6}$ and changes in the national debt. Data on high-employment tax receipts and on the national debt were not available for any of the countries. Of necessity, therefore, the only measure of fiscal infuences used in this paper is total Government spending culled from Treasury statistics on cash outlays including transfers to Government corporations. The Government component of the National Income Accounts could not be used for two reasons: 1) it included only purchases of goods and services; and 2) it included expenditures at all levels of government. Even on this basis, fiscal measures were available for only three countries. By coincidence, they were the same countries which had GNP data: Canada, Germany, and Japan. ${ }^{7}$

This limited measure of fiscal influence may not be as serious a liability as it appears. Experience with United States data indicates that Government spending is the best measure of fiscal influences. ${ }^{8}$ However, it does mean that further research on fiseal inftuences could possibly change the results presented in this article. For Belgium, France, Italy, the Netherlands, and the United Kingdom, no consistent quarterly fiscal variable was available. For these countries only monetary "influences on economic activity were measured.

It could be argued that different definitions of the money stock would be approprate for different countries because of different institutions. This is a reasonable proposition. How ever, a consistent IMF definition of money was used for two reasons: (1) the author is not familiar enongh with the institutions in each country to reformulate the money stock definition; (2) the author did not want to be accused of choosing the data source on the basis of that which best supported his hypothesis.

GActual Government spending need not be adiusted for the high-employment concept because the differences would be conceputally small. On the other hand, the difference between actual and high employment tax recepts can be conceptually large. See Keith Carlson " Estimates of the High. Employment Budget," this Review, June 1966.

7 Fiscal data were avalable for the United Kingdom from 1962 but are not induded here for reasons given in Appendix $\mathrm{H}$

8 Andersen and Jordan, pages 17 and 18 .
The results reported in this article are based on the data and sources described. However, it is conceivable that some sources of data may have been overlooked which could have improved, or perhaps modified, the results presented. ${ }^{3}$

\section{Shativical Results}

The summary results of the regression analysis in both first and central difference form, using the Almon distributed lag technique, ${ }^{10}$ are presented in Tables I and II. In the case of first differences, the quarter-toquarter change from period $(t-1)$ to period $(t)$ is labeled as the change at period $(t)$. In central difference form, the average change from $(t-1)$ to $(t+1)$ is labeled as the change at period $(t)$. Although the first difference form is the usual method of presenting "change" data, the central difference form more closely approximates the economic concept of "change" at a point in time."1

Table I includes those countries in which economic activity is measured by GNP and in which the fiscal infuence is measured by total central Government spending. Table II includes those countries in which economic activity is measured by the proxy variable and in which a fiscal variable was not available. In the Appendix, the validity of the proxy variable is discussed and it is shown that it gives substantially the same result as when GNP is used to measure economic activity. For those who are unfamiliar with interpreting statistical results as presented in Tables I and II, a description of the Canadian first difference

The sources of all data used in this article are listed at the end of the Appendix.

10In each test the form of the equation was estimated with money alone, fiscal alone, and a combination of the two. Alternative time lags between $(t-l)$ and $(t-6)$ were tried. The form of the equation selected and the time lags to represent each time period were chosen on the basis of minimum standard error of estimate adjusted for degrees of freedom.

The Almon lag technigue, by constraining the distribution of coefficients to ft a polynomial curve of $(n)$ degree, is desigtied to avoid the bias in estimating distributed-lag coefficients which may arise from multicollinearity in the lag values of the independent variables. The theoretical justification for this procedure is that the Almon constrained estimate is superior to the unconstrained estimate because it will create a distribution of coefficients which more closely approximates the distribution derived from a sample of infinite size. In order to mimimize the severity of the Almon constraint, the maximum degree of the polynomial was used in each case. The maximum degree is equal to the number of lags plus one of the independent variables up to five lags. Following the convention established by Shirley Almon, "The Distributed Lag Between Capital Appropriations and Expenditures," Econometrica, (January 1965), if there are $(n)$ lags, $(t+1)$ and $(t-n-1)$ are both constrained to zero. The regressions were also run without constraining the beginning and ending values to zero, and the results are virtually identical.

${ }^{11}$ For a futher description and justification of central differences, see John Kareken and Robert Solow, "Lags in Monetary Policy," page 18, in Stabilization Policies, Prentice Hall, 1963. 
results in Table $I$ is provided. ${ }^{12}$ Others may proceed to the section titled "Presentation of Results."

How to Read the Statistical Results - The time period (II/ 1953-IV/1968) for Canada indicates the period during which the dependent variable $(\triangle \mathrm{GNP})$ is explained by the monetary and fiscal variables. The lag (t-6) indicates that it takes the contemporary and six lagged quarters for the monetary and fiscal influences to have their full effect on the economy.

At the top of Table $I$ is an equation similar to that described on page 17 . Changes in Gross National Product ( $\triangle \mathrm{GNP}$ ) is the variable to be explained. Changes in the money stock $(\Delta \mathrm{M})$ and changes in Governm ment expenditures $(\triangle \mathrm{E})$ are the variables which are postulated to explain $\Delta \mathrm{GNP}^{13} \mathrm{a}_{1}$ is the symbol for the measured influence of $\triangle \mathrm{M}$ on $\triangle \mathrm{GNP}$, holding $\triangle \mathrm{E}$ unchanged, and $\mathrm{a}_{2}$ is the symbol for the measured influence of $\Delta \mathrm{E}$ on $\triangle \mathrm{GNP}$ holding $\triangle \mathrm{M}$ unchanged, $\mathrm{a}_{0}$ represents the estimated trend value of all other influences on $\triangle G N P$.

The columns of numbers in Table I under $\mathrm{a}_{1}$ and $a_{2}$ represent the statistically estimated value of the average relation between the monetary or fiseal influence and $\triangle \mathrm{GNP}$ for various countries. In the case of Canada, 4.27 is the estimated monetary coefficient, which implies that on the average, for every $\$ 1$. increase in the money stock, there will be a $\$ 4.27$ increase in GNP over the current and six following quarters. The number below, enclosed by a parentheses $(5.75)$, is the " $\mathrm{t}$ " statistic, which is a measure of the statistical confidence one may have that the estimated coefficient has the same sign as the "true" coefficient relating $\triangle \mathrm{M}$ to $\triangle \mathrm{GNP}$. The larger the "t" statistic, the greater our confidence in the value of the estimated coefficient. In general, an estimated coefficient with a " $\mathrm{t}$ " statistic larger than 1.96 is signi-

12It should be kept in mind that this description is highly simplified. Those who are interested in a more complete and rigorous explanation of statistical hypothesis-testing should consult any elementary textbook in statistics.

$13 \triangle E$ rather than $\triangle F$ is used here as a symbol of the fiscal influence because the specific measure used in this case is changes in Government expenditures. $\Delta F$ was a surrogate for any measure of fiscal influence. ficantly different from zero, and a " $\mathrm{t}$ " statistic smaller than 1.96 is not significantly different from zero at the 95 per cent confidence level. The convention in economics is to make the 95 per cent confidence interval the boundry between acceptance or rejection of the coefficient as significantly different from zero. Thus, in the case of Canada, the statistical results indicate that the monetary influence is positive and highly significant.

The estimated coefficient for the fiscal influences for Canada is -1.45 . The implication is that for every $\$ 1$ increase in Government expenditures, there will be a $\$ 1.45$ decrease in GNP after six quarters. This negative relation is contrary to the generally assumed relation between Government spending and GNP. However, the " $\mathrm{t}$ " statistic of $(1.38)$ indicates the estimated fiscal coefficient is not statistically different from zero, and consequently this result is not persuasive evidence that Government expenditures are perverse in their effect on economic activity. The $R^{2}$ is the coefficient of determination adjusted for degrees of freedom. ${ }^{14}$ It is .43 for Canada. This means that

\footnotetext{
14The degrees of freedom of an equation are equal to the number of observations of the dependent variable minus the number of independent variables, including the constant term. In the Canadian case, there were 63 observations of $\triangle \mathrm{GNP}$ from $\mathrm{I} / 1953$ to $I V / 1968$ and there were 7 independent money variables (one contemporary and six lagged), and 7 independent fiscal variables plus one constant term, so that the degrees of freedom equalled 48 .
} 
43 per cent of the variation in $\triangle \mathrm{GNP}$ can be explained by variation in the monetary and fiscal variables, $\Delta \mathrm{M}$ and $\Delta \mathrm{E}$.

Considering that the statistical estimates were made on the basis of quarterly first differences, which magnifies the random elements in the data, an $R^{2}=.43$ is considered to be reasonably high. D-W (the DurbinWatson statistic) is a measure of randomness in the error term of the estimated equation. An acceptable range for the $\mathrm{D}-\mathrm{W}$ statistic in these equations would be roughly between 1.25 and $2.75 .^{15}$

Presentation of Results - Table I shows the summary regression results for Canada, Germany, Japan and the United States, using changes in quarterly GNP as a measure of economic activity. In each case the results are presented in both first difference and central difference form. Central difference data are, in effect, a two-term moving average of first difference data. Thus, central differences have consistently higher $\mathrm{R}^{2}$ than first differences because some of the random movements which are so prominent in first difference data have been averaged out. This also has the effect of reducing the randomness of the error term and thus redueing the value of the Durbin-Watson statistic. ${ }^{16}$

The regression results in Table I give substantially consistent implications with respect to monetary influences. In every country the coefficient for the monetary variable is positive and statistically significant in both first and central difference form. On the other hand, the fiscal variable does not exert an influence which exhibits any systematic pattern for the various countries. For Canada the

15This is based on the assumption of 40 observations and 5 independ. ent variables. One could reject auto correlation in the error term (lack of randomness) if the DurbinWatson statistic is in the range 1.79-2.21. The inconclusive range goes as low as 1.25 and as high as 2.75. The inconclusive range would be narrowed with more observations and widened with more independent variables.

16there seems to be a systematic trade-off between first and central differences, with the latter having higher $R^{2^{*}} \mathrm{~s}$ (which is desirable) and lower D-W statistics (which is sometimes undesirable). fiscal variable is insignificant in first differences and negative and significant in central differences. For Germany and the United States, it is statistically insignificant in both first and central difference form. For Japan, the fiscal variable is statistically insignificant in first differences and positive and statistically significant in central differences. These results contrast sharply with those for the monetary variable where, for each country, and for both first and central differences, the monetary coefficient is positive and statistically significant.

The other countries in this study do not have quarterly GNP estimates which can be used as a measure of economic activity. For those countries economic activity is measured by the proxy variable defined above and justified in the Appendix.

In Belgium, France, Italy, the Netherlands, and the United Kingdom (before 1962), acceptable measures of fiscal influence are not available. For these countries, it was only possible to measure monetary influences on economic activity. This is done in Table II with quarterly observations from 1953 to 1968 , using both first and central difference form.

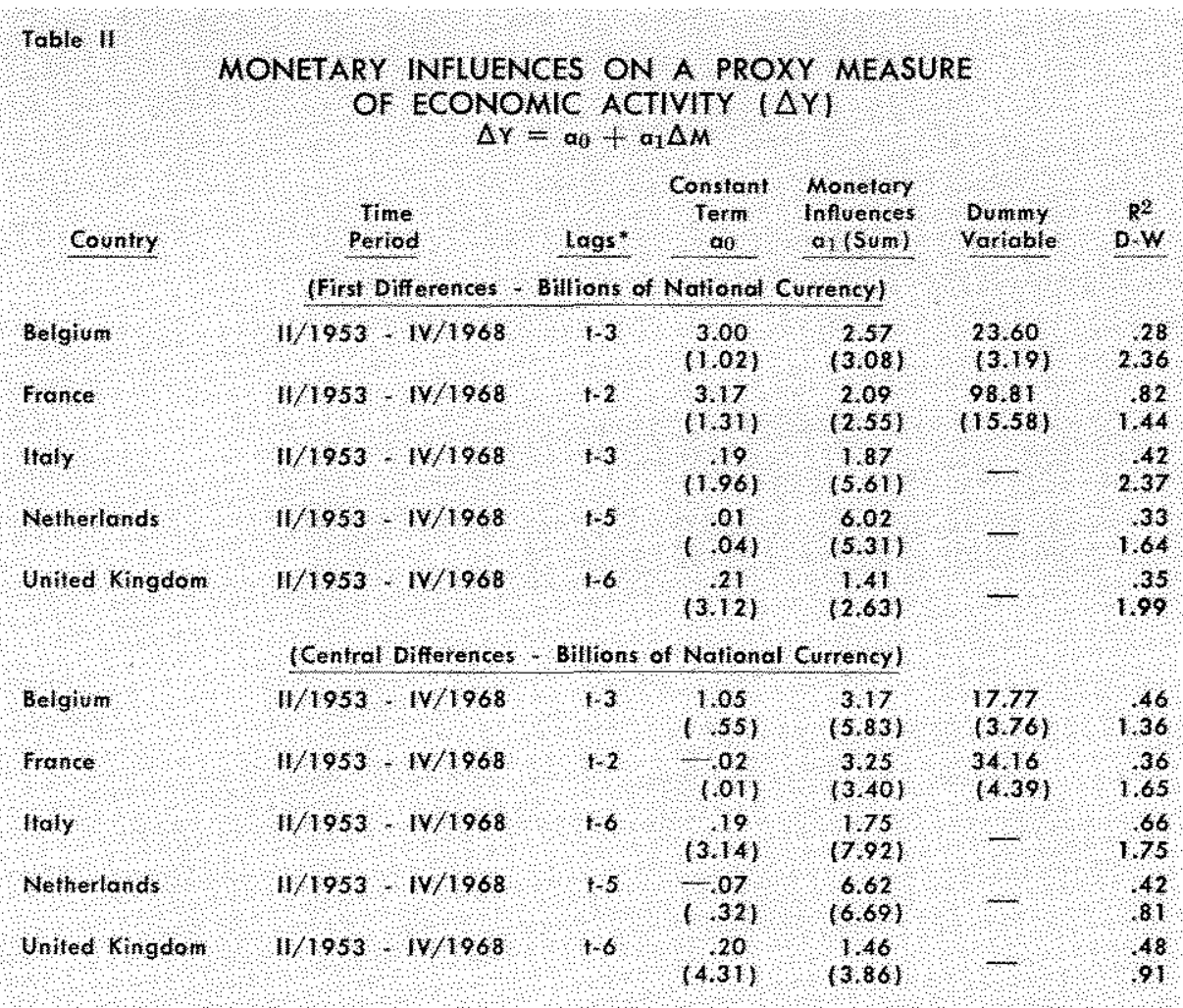

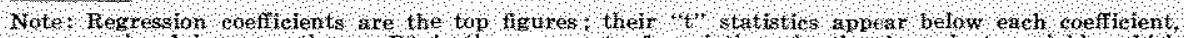

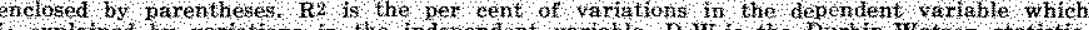

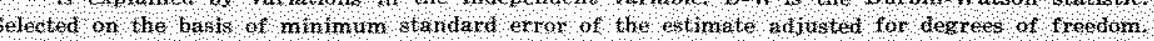


In the case of Belgium and France, dummy variables were added to account for major nation-wide strikes. ${ }^{17}$ In Belgium, there was a nation-wide strike in December 1960 and January 1961 which closed down most major industries. To account for this nonmonetary influence on economic activity, a dummy variable was included which assumed the value of -1 in IV/1960-I/1961 and a value of +1 in II/1961. For all other periods the dummy variable had a value of zero. In France, there was a nation-wide strike in May 1968 which shut down virtually all industry. As monetary inftuences would not be expected to explain this phenomenon, a dummy variable was included which assumed the value of -1 in the second quarter of 1968 and +1 in the third quarter of 1968. The dummy variable assumed a value of zero for all other quarters. For France the statistical significance of the dummy variable was substantial in first differences and much less so in central differences, because the impact of the strike was partially averaged out in central difference data. Consequently, the high $\mathrm{R}^{2}$ for French first difference results (.82) should be partially discounted.

Although the monetary influence is statistically sig. nificant for every country in this study, there is a substantial degree of variation in the estimated value of the monetary influence between countries. For example, in first-difference form the monetary variable for Germany is 8.88 , and for the United Kingdom it is 1.41 . This range of values is largely due to variations in institutional factors in each country, such as the level of per capita income, the traditional payment period for workers, and the number and availability of money substitutes.

\begin{tabular}{|c|c|c|}
\hline & $\begin{array}{l}\text { Monetary } \\
\text { Influente } \\
\text { (a) }\end{array}$ & $\begin{array}{l}\text { Velocty } \\
\text { GNP M }\end{array}$ \\
\hline 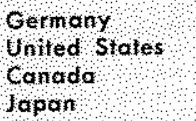 & $\begin{array}{l}8,80 \\
5,50 \\
2,7 \\
278\end{array}$ & $\begin{array}{l}6,60 \\
456 \\
5,14 \\
360\end{array}$ \\
\hline 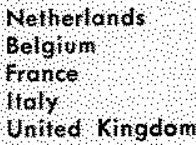 & $\begin{array}{l}602 \\
257 \\
209 \\
167 \\
1,1\end{array}$ & $\begin{array}{l}427 \\
285 \\
296 \\
273 \\
270\end{array}$ \\
\hline
\end{tabular}

These institutional factors can substantially influence the amount of money stock required to induce a given change in economic activity. One rough measure of the institutional differences between countries is the observed ratio of the money stock to income

17There were undoubtedly random events in other countries which could have been accounted for with dunmy variables. (the income velocity of money). As can be seen in Table III, the estimated value of the monetary influence for each country $\left(a_{1}\right)$, is closely associated with the income velocity of money.

The monetary influence values are derived from first-difference results in Tables I and II. The values for velocity (GNP/M) are calculated on the basis of annual GNP and money stock data for 1968. These results indicate that the monetary influence values are substantially intuenced by the institutional factors which determine velocity in each country. However, as these institutional factors seem to change only slowly over time, the monetary influence values are relatively stable within each country.

The results presented in Table $\mathrm{II}$, where monetary influences alone are measured, are consistent with the results in Table $I$ in which both monetary and fiscal influences are measured. The monetary influence is positive and statistically significant in all countries considered in both first and central difference forms of the equation. The $\mathrm{R}^{2}$ s $\mathrm{s}$ are sufficiently high to infer that monetary influences explain a significant amount of the change in economic activity in these countries. Every substantial movement in money is followed by a roughly proportional movement in economic activity,

The results presented in Tables I and II indicate that in nine of the major industrial countries of the world, monetary influences play an important role in determining the short-run movements in economic activity.

\section{Testing Propositions}

Three propositions with respect to monetary and fiscal influences were tested in earlier articles on the basis of United States results. These propositions considered whether monetary or fiscal actions were (1) stronger, (2) more predictable, and (3) faster-acting. The conclusion reached with respect to the United States was that monetary actions dominated fiscal actions in each proposition.

These same propositions will be tested for foreign countries in which both monetary and fiscal measures are available; that is, Canada, Germany, and Japan. In addition, updated results for the United States will be presented as a basis for comparison.

Which is stronger - To measure the relative strength of monetary and fiscal influences during the test period we need to know which has had the largest impact on economic activity. If the monetary 


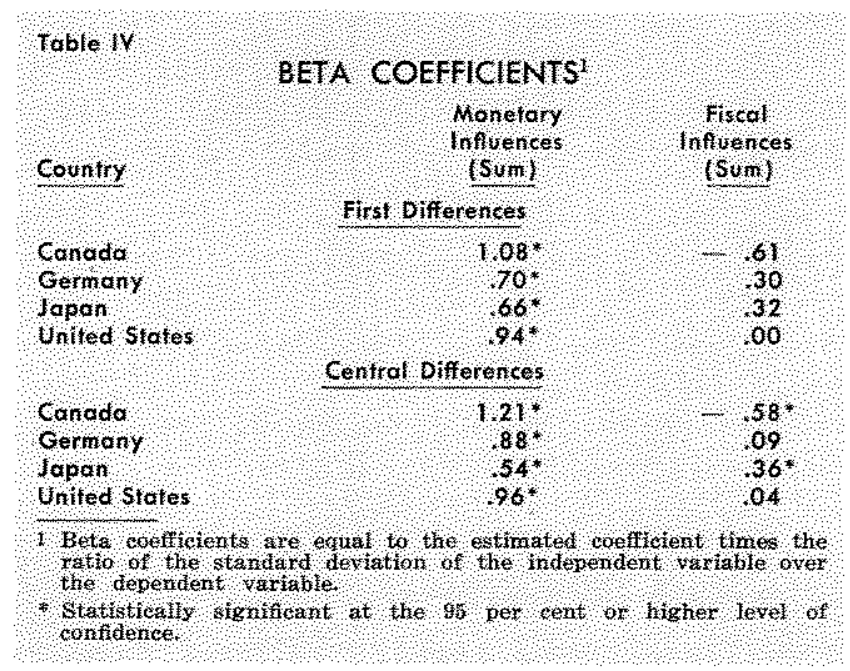

and fiscal measures had the same dimension and the same average degree of variation, the test could be made by directly comparing the size of the estimated coefficients of the monetary and fiscal variables. As these conditions are not satisfied, the estimated coefficients cannot be used directly for this test. However, when the estimated coefficients are "normalized" by being converted into beta coefficients, they can be compared. ${ }^{18}$ The "sum" beta coefficients for Canada, Germany, Japan, and the United States are presented in Table IV for both first and central difference form.

The results indicate a considerable degree of consistency between countries. In every country for both first and central differences, the beta coefficients for the monetary variable are substantially larger than that for the fiscal variable. In every case the sign of the monetary variable is positive (a change in money leads to a change in GNP in the same direction), and the values are statistically significant. The sign of the beta coefficient for the fiscal variable varies between countries and is statistically significant only for Canada and Japan in central difference form. However, the values of the fiscal coefficients in these two countries are opposite in sign, indicating a lack of cross-country consistency. Clearly, for the time periods and countries considered, monetary influences have had a stronger impact on economic activity than have fiscal influences.

Which is more predictable? - The best-known measure of the predictability of the monetary and fiscal influences on economic activity is the " $t$ " statistic,

\footnotetext{
18Beta coefficients are equal to the estimated coefficient times the standard deviation of independent variable over the standard deviation of the dependent variable. See Arthur S. Goldberger, Economic Theory, (John Wiley and Sons, $1964)$, pp. $197-98$.
}

As indicated above, the " $\mathrm{t}$ " statistic is a statistical indicator of the confidence one may have that the "true" relationship between the independent and the dependent variables has the same sign as that of the statistically estimated relationship between those variables. The larger the " $t$ " statistic, the more confidence one may have that the monetary and fiscal variables are predictably related to economic activity. The sum " $\mathrm{t}$ " statistics of the monetary and fiscal coefficients included in Table I are reported separately in Table $V$ for both first and central differences. Again, the results are remarkably consistent between countries. In every case the " $\mathrm{t}$ " statistic for the monetary coefficient is larger than the " $t$ " statistic for the fiscal coefficient. As a crude indicator of the relative precision of coefficient estimates, the absolute value of the average " $\mathrm{t}$ " statistic of the monetary variable is $41 / 2$ times larger than that of the fiscal variable. Thus, for the four countries considered, the monetary varia ble is substantially more predictable in its effect on GNP than the fiscal variable.

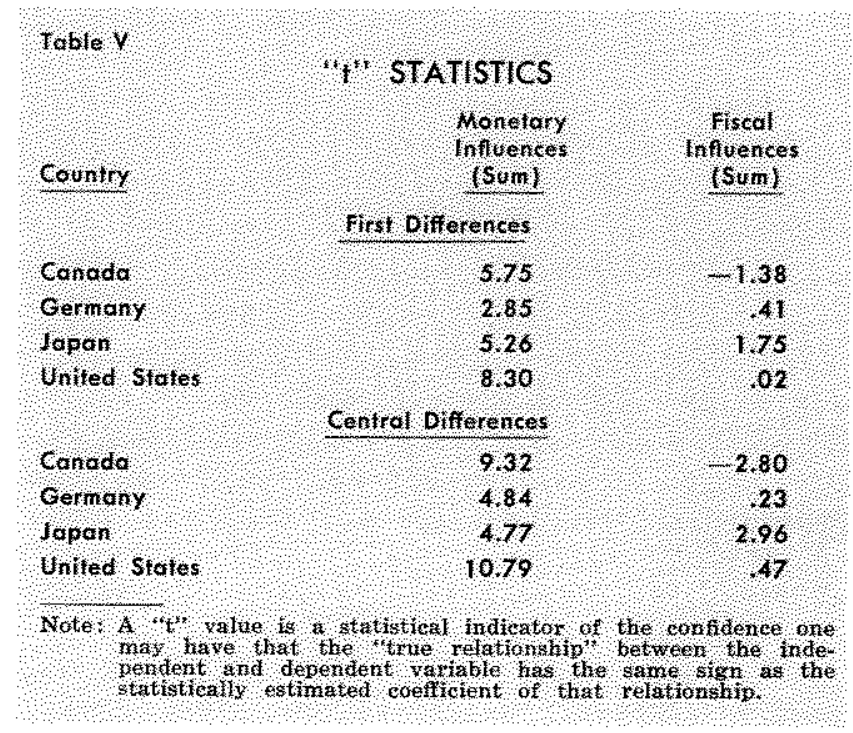

Which works faster. - The relative speed of monetary or fiscal influences can be measured by observing which variable has the shorter time lag in influencing economic activity. For comparability, the quarterly patterns of the estimated beta coefficients are used. The beta coefficient results were derived from the same set of statistical results summarized in Table I. Only the first difference results are plotted in Chart I. Almost identical patterns of beta coefficients are obtained with the central-difference form. Again, the quarterly pattern of the monetary influence on economic activity is remarkably stable for different countries. In contrast, the quarterly pattern of fiscal influence on economic activity varies substantially be- 
between countries. For each country, the effects of the monetary influence substantially outweigh the effects of the fiscal influence in the contemporary quarter, except for the case of Japan. In Japan, where the fiscal influence has had the largest overall positive association of any of the countries considered, the monetary influence outweighed the fiscal influence in the first and second lagged quarters. The general impression from observing the quarterly pattern of the beta coefficients is that monetary influences tend to have a faster impact on GNP than fiscal influences for these four countries.

The results of testing these three propositions about monetary and fiscal influences on economic activity for Canada, Germany, and Japan are consistent with the results obtained from earlier studies on the United States.

\section{Additional Observations in the Money-Economic Activity Relation}

Two points should be kept in mind in interpreting these results:

1) Monetary influences have a large and systematic influence on economic activity. Because policymakers can control the money stock, monetary policy should play a central role in any successful stabilization policy.

2) The high degree of statistical association between monetary influences and economic activity should not be taken to imply that there are no other systematic influences operating on economic activity. Economic activity can be influenced by a wide range of factors which are independent of monetary influences. A demonstration of this fact is that the degree of variation in economic activity, explained by monetary influences is less than perfect.

Both of these points can be highlighted with examples from three countries.

Germany - Chart II illustrates that from 1954 to 1964, German monetary influences were relatively

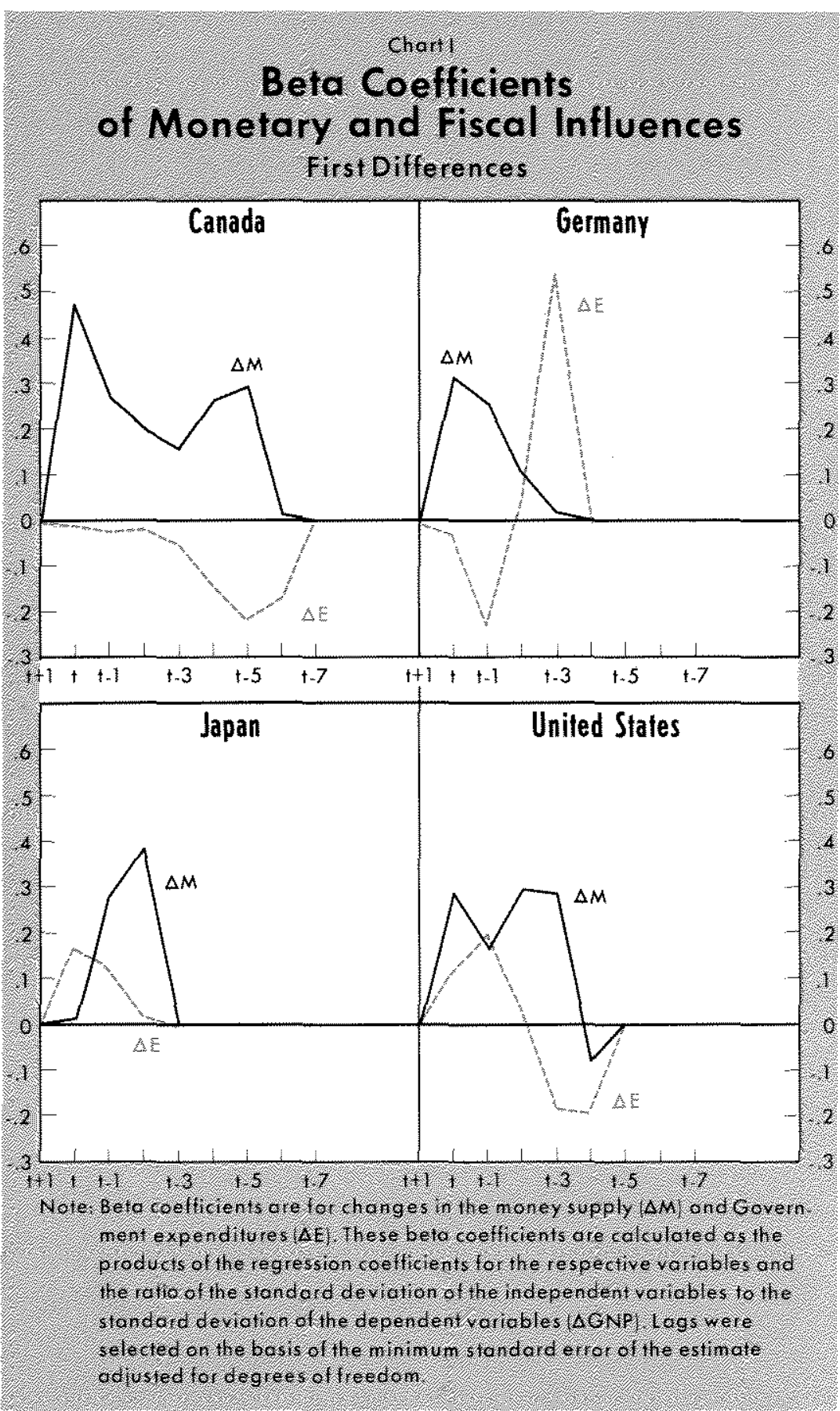

stable as measured by the quarter-to-quarter changes in the money stock. With the exception of a moderate deceleration in 1959 and 1960 , no cyclical pattern can be observed in the money stock. Economic activity during the 1954-64 period also exhibited a relatively stable growth rate. However, there were several moderate fluctuations with cyclical tronghs in 1958,1960 , and 1962. Yet only the trough in 1960 was associated with restrictive monetary influences. Although none of these cyclical movements in economic activity 


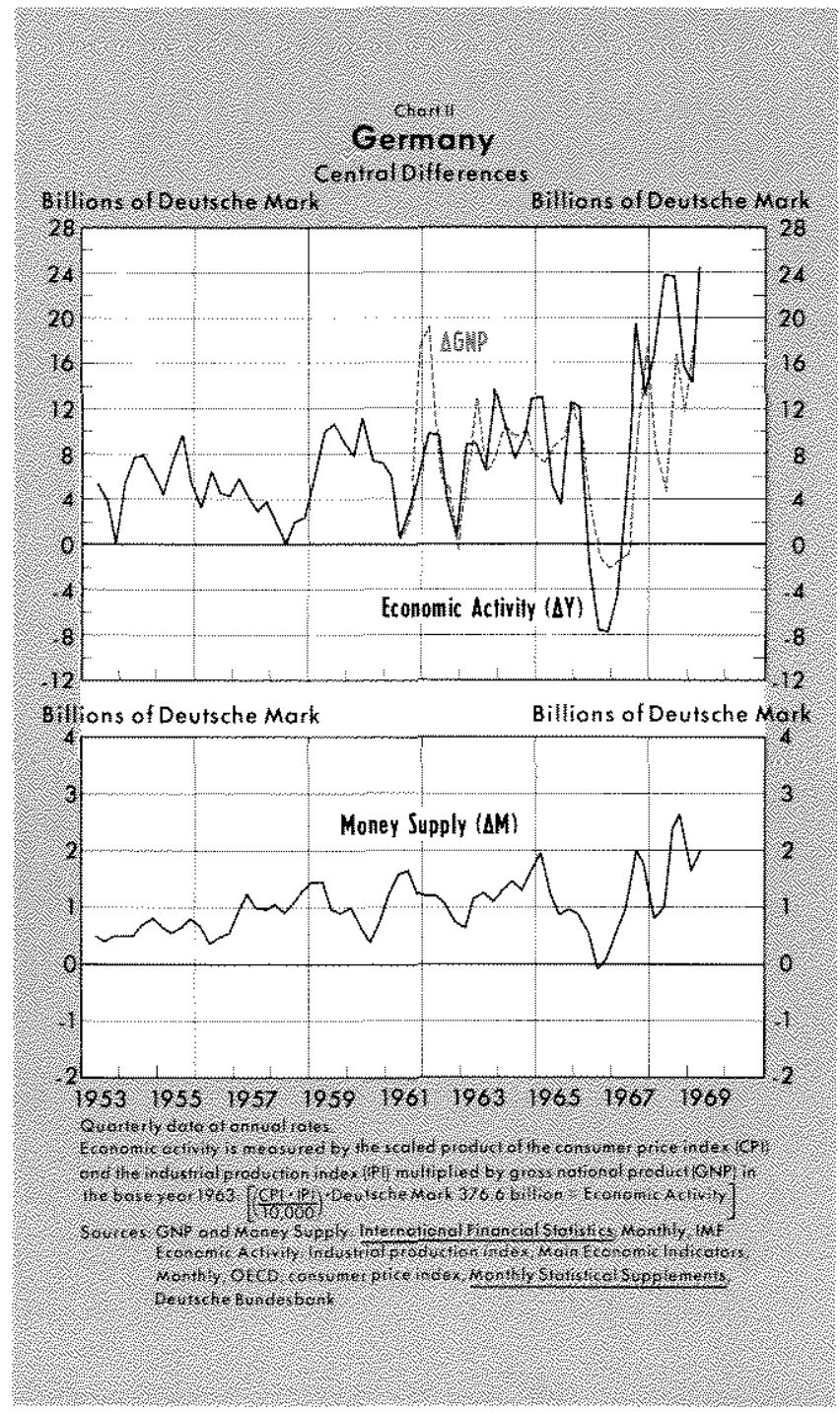

were sufficiently strong to have been generally considered a recession, they illustrate that cyclical movements in economic activity do occur independently of monetary influences. ${ }^{19}$

German developments in the 1965 to 1969 period, moreover, provide an example of the strength of monetary influences when they are allowed to operate. In late 1965 and in 1966 the German monetary authorities followed a systematically restrictive policy, as indicated by the steady deceleration of the money stock. This monetary action was, in part, a response

19 This raises an important point in statistical estimation procedures. A regression analysis on German data from 1954 to 1964 would not have shown a statistically significant association between monetary variables and economic activity. The method of computing statistical association is that variations in one variable are observed to occur systematically with variations in another variable. If there is little or no variation in monetary variable, then the statistical regression procedures will not measure any significant relation with economic activity. to fears of domestic inflation, although in the main it was due to concern over deterioration of the German international trade position. ${ }^{20}$ This restrictive monetary policy was followed by a substantial deceleration in economic activity in late 1966 and 1967. As the international trade position improved, monetary policy was eased, and the money stock accelerated in 1967 and 1968. Economic activity responded promptly, resuming the rapid growth rates of earlier years. The 1966-67 business cycle trough was widely recognized in Germany as a period of recession, and its cause can be clearly traced to the actions of the monetary authorities.

German postwar experience illustrates two things: first, stable monetary influences do not exclude the possibility of cyclical instability in the economy; and second, fluctuating monetary influences seemingly induce fluctuations in economic activity.

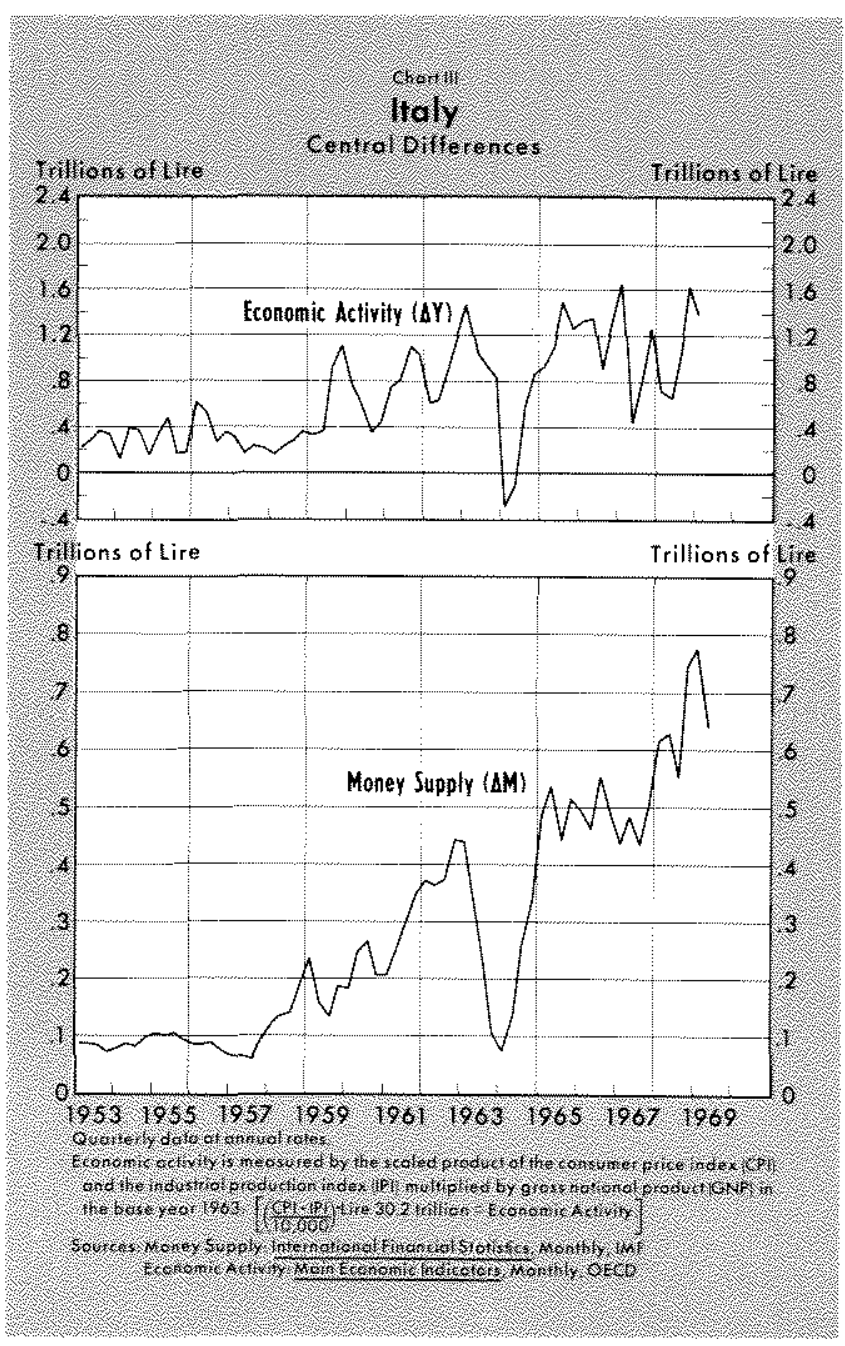

20See Michael Keran "Monetary Policy, Batance of Payments, and Business Cycles: The Foreign Experience," this Review, November 1967. 
Italy -- Chart III illustrates that the Italian experience in the post-war period is similar to that of Germany. From 1953 to 1957, monetary influences in Italy were stable and economic activity grew at a relatively stable rate, with some irregular quarter-toquarter movements. From 1958 to 1962 the money stock accelerated and, correspondingly, economic activity accelerated. Because of a deterioration in their international trade position in 1962 and 1963, the Italian monetary authorities followed a tight money policy in 1963 and early 1964. Their actions caused a sharp deceleration in economic activity in late 1963 and into 1964. When the money stock was permitted to accelerate in the second half of 1964 , conomic activity expanded in line with its previous growth rate. Italy has had stable growth in both money and economic activity since 1965, despite its widely publicized political turmoil.

Japan-The Japanese experience contrasts with that of Germany and Italy in its more frequent reversals of monetary actions, as shown in the lower tier of Chart IV. This monetary behavior has apparently caused all postwar business cycles in Japan to be dominated by monetary considerations. Japan has had four cyclical troughs: in 1954, 1957, 1962, and 1965. Each of these troughs was preceded by a deceleration in the money stock and each recovery with an acceleration in the money stock. All systematic movements in economic activity in Japan have been related to monetary considerations. From 1965 to 1968, Japan followed a stable monetary policy and, as a result, economic activity has also grown at a relatively stable rate until very recently.

The Japanese experience reinforces the points made above. Although stable monetary influences do not guarantee stable growth in economic activity, unstable monetary influences seem to assure fluctuations in the growth of economic activity.

\section{Conclusion}

The purpose of this article has been to review the postwar economic experience of a variety of industrial countries to see whether monetary and fiscal influence bear any systematic relationship to movements in economic activity. The results presented indicate that in spite of admitted differences in cconomic institutions and differences in the objectives of policymakers between countries, a substantial degree of consistency is observed. For each of the eight foreign countries considered, the monetary influence was important. The estimated coefficient relating the monetary variable to economic activity was positive and statistically significant. Of the countries in which fiscal measures

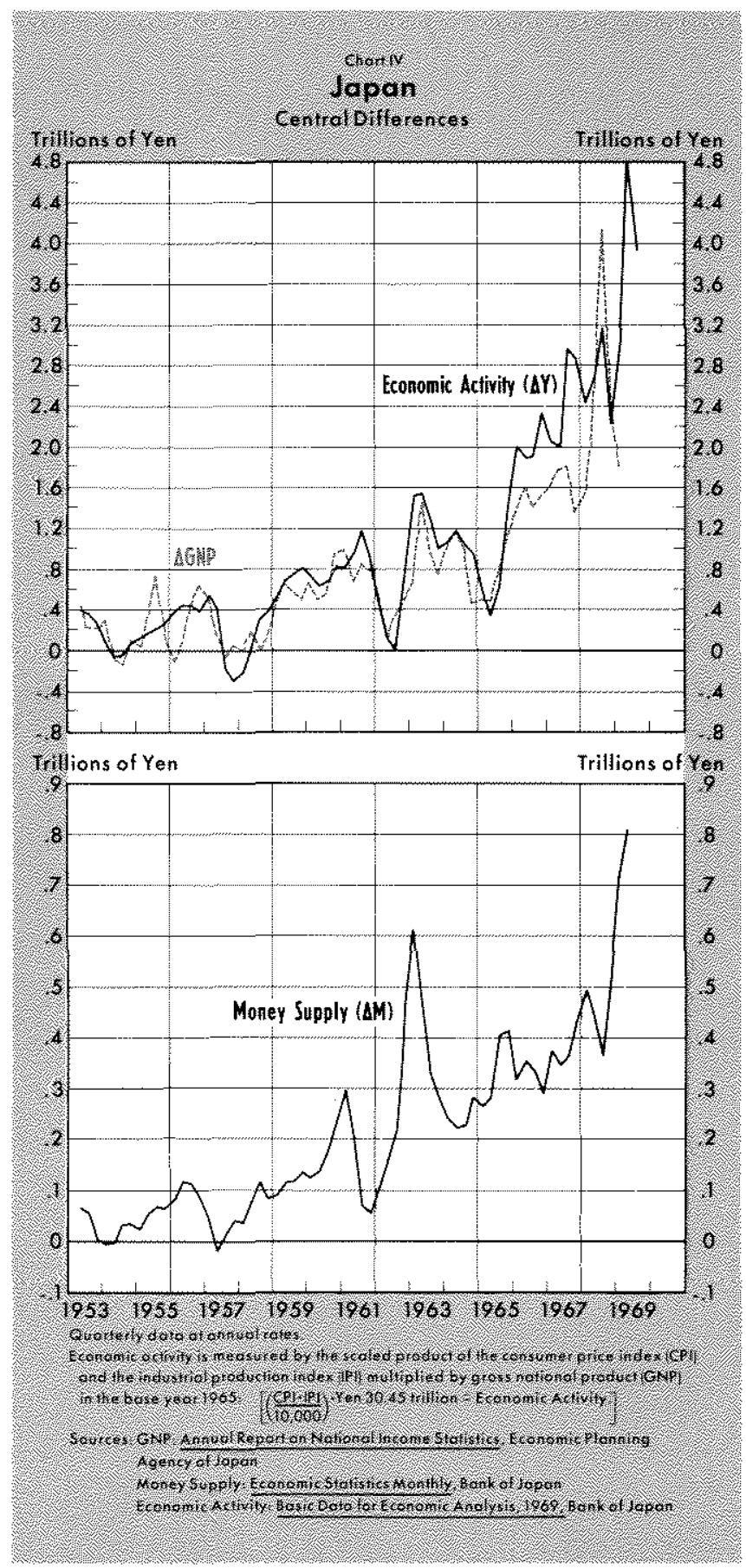

were available, only in Japan was the positive relation postulated by economic theory found to hold.

It is important to keep in mind that these results, especially with respect to fiscal influences, are even more tentative than is generally the case in statistical estimations of economic relations, because of the severe data limitations discussed above.

With this caveat the implication of this study is that our confidence in the results of earlier studies 
which were based on United States data, is enhanced. The single equation approach to measuring monetary and fiscal influences on economic activity, which was developed for the United States, has passed the "forecasting test" mentioned at the beginning of this article. That is, the recent economic experience of a number of industrial countries can be better understood by the use of this equation.
Previous research which concluded that monetary influences are important in determining the shortrun movements in economic activity is confirmed by the results obtained for other countries.

This article is avaluble as Reprint No. 52.

The Appendix to this article develops the case for using a proxy measure of economic activity for those countries in which quarterly GNP data are not available. The Appendix also considers the special case of the United Kingdom.

\section{APPENDIX}

\section{Compather Nomind GNP und a prow Meastre of Ecomonte inchive}

Nominal GNP is a measure of the market value of all goods and services produced in an economy duning a particular time period. It is the most broad-based measure of economic activity available. But since quarterly GNP data are not available for many important countries, a proxy for economic activity was constructed and used in some cases. This altemative measure is equal to the scaled prodact of the consumer price index (CPI) and industrial production index (IPI) times GNP. The formula for computing the proxy for economic activity (Y) is:

$$
\mathrm{Y}=\left(\frac{\mathrm{CPI} \cdot \mathrm{IPI}}{10,000}\right) \cdot \mathrm{GNP}
$$

where the value of GNP is that in the base year of the price and production indexes.
The proxy meastre of economic activity has a much narrower base than GNP. The price component of the proxy was measured only by the consumer price index (CPI). However, the CPI tends to move quite closely with movements in the implicit GNP price dellator for those countries in which we have both data series. The real component of the alternative measure is based on the seasonaly adjusted industrial production index, which means that all service industries, levels of government, and agriculture are not included.

Despite these limitations, this measure of economic activity is a useful first approximation for the purposes of business cycles analysis. Its usefulness is indicated in Table VI, where economic activity is measured by our proxy variable and by nominal GNP for those countries in which both series are avalable. As can be seen, the indicator's of monetary and fiscal influences give consistently the same results with these different meastres 


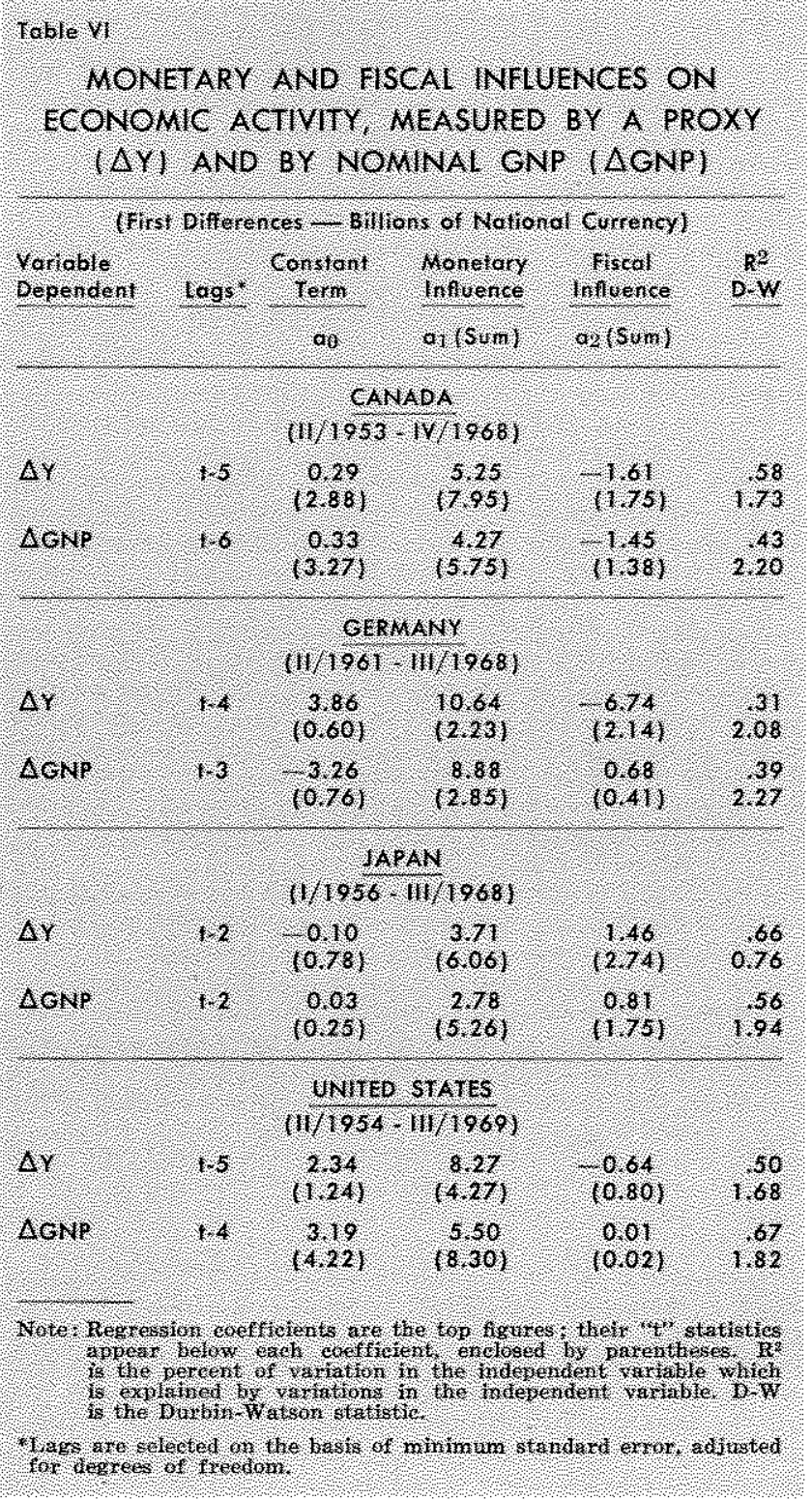

of economic activity. The coefficient for the monetary variable is positive and statistically significant for each country using both measures of economic activity. The coefficient for the fiscal variable tends to vary in sign and significance from country to country.

Another indication of the reasonableness of the proxy vanable $(\Delta Y)$ is that the quarterly pattem of the beta coefficients for each country with respect to $(\Delta M)$ and $(\Delta \mathrm{E})$ is almost identical to that presented in Chart $\mathrm{I}$ for ( $\triangle \mathrm{GNP}$ ). The values of the monetary and fiscal variables with respect to $\triangle \mathrm{Y}$ and $\triangle \mathrm{GNP}$, can be compared directly because the proxy variable has been scaled by the value of GNP.

The results presented in Table VI indicate that in some cases the monetary and fiscal variables do a better job of explaining the proxy. variable $(\Delta Y)$ than they do of explaining changes in GNP ( $\triangle \mathrm{GNP}$ ). For both Canada and Japan the $\mathbf{R}^{2}$ for the proxy variable $(\Delta Y)$ is larger than that for $\triangle G N P$. In the United States and Germany the $\mathrm{R}^{2}$ is higher for $\triangle G N P$ than it is for the proxy variable $(\Delta \mathrm{Y})$. These results imply that the proxy variable is a useful measure of economic activity, permitting meaningful estimates of monetary and fiscal influences.

\section{The Special Case of the United Kangdom}

The results for the United Kingdom are consistent with the results for the other countries, when economic activity is measured by the proxy variable (see Table II in the main body of this article). However, when economic activity is measured by GNP or, as the English prefer, GDP1, the results are not statistically significant. This can be seen in the first difference results presented in Table VII.

Table VII presents the estimated relationships between monetary and fiscal influences and three different measures of economic activity. When economic activity is measured by the proxy variable $(\Delta Y)$, the monetary infuence is statistically significant and the fiscal influence is not. Together the monetary and fiscal variables explain 21 per cent of the variation in $(\Delta \mathrm{Y})$. When economic

IGDP stands for Gross Domestic Product. The major difference between this and GNP is the way in which the international sector is handled. In CDP, net receipts from interest, profits, and dividends earned abroad are excluded, while in GNP they are included.

Toble vil

\section{UNITED KINGDOM}

Morretary and Fisca. Infuences on Economic Activity Measured A, A Proxy 12 Y, Nominal GNP (LONPI, and Nominal GBP 1 LGOPI

\begin{tabular}{|c|c|c|c|c|c|}
\hline Deperdent & logst & $\begin{array}{l}\text { Constonit } \\
\text { remin } \\
\text { oo }\end{array}$ & $\begin{array}{l}\text { Monetary } \\
\text { linfuerce } \\
\text { an (sun) }\end{array}$ & $\begin{array}{l}\text { Fised } \\
\text { arfuence } \\
\text { a. (Som) }\end{array}$ & ow \\
\hline \multicolumn{6}{|c|}{ (first Differentes. Billons of Pound Sterling) } \\
\hline$\Delta$ & 12 & $(7,3)$ & 1,50, & $\begin{array}{l}(.37 \\
(1.00)\end{array}$ & $\begin{array}{l}2.1 \\
198\end{array}$ \\
\hline$\Delta 0,1$ & 12 & $(2,40)$ & $(801)$ & $(4,63)$ & $\begin{array}{l}105 \\
3.16\end{array}$ \\
\hline$\triangle G D P$ & & $(2,54$ & $\sqrt{58}$ & 4.1011 & 3.02 \\
\hline \multicolumn{6}{|c|}{ 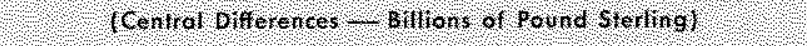 } \\
\hline$\Delta y$ & 42 & $(1 / 13$ & $(2,54,5)$ & $\left(\begin{array}{l}100 \\
1991\end{array}\right.$ & 1,35 \\
\hline AGNP & 106 & $(2,396$ & $(1.0406$ & $(1,3,4)$ & $\begin{array}{l}30 \\
236\end{array}$ \\
\hline 9 & 18 & $(2,67)$ & 91.22 & $(1.65$ & 2,10 \\
\hline
\end{tabular}

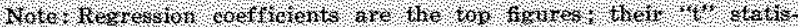

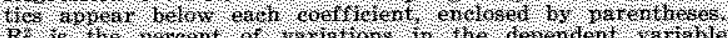

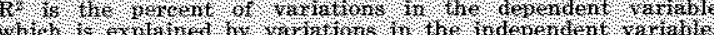

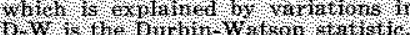

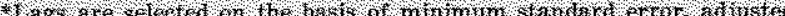
$0010+0.0 \%$ 
activity is measured by $\triangle \mathrm{GNP}$ or $\triangle \mathrm{GDP}$, neither the monetary nor the fiscal influences are statistically signifcant, and the amount of variation in economic activity explained by these variables is only 5 per cent and 2 per cent, respectively, in first difference form.

Quite clearly, when economic activity is measured in first difference form, the proxy variable $(\Delta \mathrm{Y})$ gives an entirely different assessment of the influences of monetary and fiscal variables than does $\triangle G N P$ or $\triangle G D P$. These differing results using alternative measures of economic activity are not observed for the other countries in this study. For every other country $\Delta \mathrm{Y}$ and $\triangle \mathrm{GNP}$ gave substantially the same results with respect to the monetary and fiscal variables.

An investigation of the time series of GNP and the proxy measure of economic activity provides at least a partial explanation for this discrepancy. Both series show the same basic cyclical pattern in first-difference form. However, the GNP series has a small number of quarterly observations which deviate substantially from the proxy measure series. This is especially true for the third and fourth quarters of 1963 , the first and second quarters of 1967, and the second and third quarters of 1968 . These deviations tend to be offsetting, that is, a sharp decline in one quarter is matched by a sharp increase in the next quarter. With only 27 observations in the sample period, even six atypical observations can distort the statistical significance of the estimated coefficients.

These atypical observations could be due to the fact that both the GNP and GDP data have greater measurement error than the data which underlies the proxy measure of economic activity. Both the industrial production and consumer price indexes are monthly series which are averaged to compute quarterly proxy meas" ures. The measurement error possibility is consistent with the very large Durbin-Watson statistic (3.18) for firstdifference results of both GNP and GDP, which implies a high degree of negative auto-correlation in the error term. When central differences are taken of the GNP and GDP data, the consequences of random-measurement error in the series are reduced. The offsetting movements in the quarterly values $\triangle \mathrm{GNP}$ and $\triangle \mathrm{GDP}$ are considerably lessened.

Measuring monetary and fiscal infuences against central differences (see bottom half of Table VII), one observes that both the monetary and fiscal variables are statistically significant with respect to GNP, and the explained variation of $\triangle \mathrm{GNP}$ rises to 30 per cent. The value of the Durbin-Watson statistic is also in a less unacceptable range than in the first difference results. Computing central differences for $\triangle G D P$ does not improve the results significanty from the first difference results. ${ }^{2}$

These results suggest that perhaps a proxy variable may be superior to GNP or GDP as a measure of economic activity, if there is less measurement error in the proxy variable than in the other measures of economic activity.

The relatively short period from $\mathrm{I} / 1962$ to III/1968 was used for the regressions in Table VII because total

2M. J. Artis and A, R. Nobay, "Two Aspects of the Monetary Debate," in National Institute of Economic Review, August 1969 , report similar results with respect to $\triangle \mathrm{CDP}$. government spending data were not available in earlier years. A longer time span encompassing a wider range of economic events (1953-68) was used in the main body of the article to analyze monetary influences in the United Kingdom.

\section{Data Sources}

For each country the seasonally adjusted series for the industrial production index, Gross National Product, money stock, and Government expenditures were used. The consumer price index is not seasonaly adjusted.

Belgium - Industrial production index and consumer price index, 1963-100; Main Economic Indicators, OECD; Money Stock: International Financial Statistics, $\mathrm{MFF}^{4}$.

Canada - Industrial production index and consumer price index, $1963=100$, Main Economic Indicators, OECD; Gross National Product; Canadian Statistical Review, Dominion Bureau of Statistics; Money Stock: International Financial Statistics, IMF; Government Expenditures: Canadian Statistical Review, Dominion Bureau of Statistics.

France - Industrial production index and consumer price index, 1963=100; Main Economic Indicators, OECD; Money Stock: International Financial Statistics, IMF.

Germany - Industrial production index, 1963=100 Main Economic Indicators, $\mathrm{OECD}$; consumer price index, $1962=100 ;$ Monthly Statistical Supplements, Deutsche Bundesbank; Gross National Product and Money Stock: International Financial Statistics, IMF; Government Expenditures: Monthly Report of the Deutsche Bundesbank.

Italy - Industrial production index and consumer price index, 1963=100: Main Economic Indicators, OECD; Money Stock: International Financial Statistics, IMF.

Japan - Industrial production index and Consumer price index, 1965=100: Basic Data for Economic Analysis, 1969, Bank of Japan; Gross National Product: Annual Report on National Income Statistics, Economic Planning Agency of Japan; Money Stock: Economic Statistics Monthly, Bank of Japan; Govermment Expenditures: Basic Data for Economic Analysis, 1969, Bank of Japan.

Netherlands - Industrial production index and consumer price index, $1963=100:$ Main Economic Indicators, OECD; Money Stock: International Financial Statistics, IMF.

United Kingdom - Industrial production index and consumer price index, 1963=100: Main Economic Indicators, OECD; Money Stock: International Financial Statistics, IMF; Govermment Expenditures: United Kingdom Financial Statistics.

United States - Industrial production index, 1957-59= 100: Board of Governors of the Federal Reserve System; consumer price index, 1957 $59=100$ : United States Department of Labor; Gross National Product: United States Department of Commerce; Money Stock: International Financial Statistics, IMF; Govermment Expenditures: Federal Reserve Bank of St. Louis. 